\title{
Simulation and Analysis of a Petrochemical Process (Deethanizer Column- MLE field) using HYSYS Aspen Simulator.
}

\author{
BELHOCINE Amel $^{(1)}$, BENDIB Riad ${ }^{(2)}$, ZENNIR Youcef ${ }^{(3)}$ \\ (1) Department of petrochemical and process engineering. University of Skikda, Skikda, Algeria \\ (2) Department of petrochemical and process engineering. University of Skikda, Skikda, Algeria \\ (3) Department of petrochemical and process engineering. University of Skikda, Skikda, Algeria \\ amelbelhocine42@gmail.com r.bendib@univ-skikda.com y.zennir@univ-skikda.dz
}

\begin{abstract}
Natural gas industry has a great strategic and economic importance; it becomes one of the most attractive business opportunities in the petroleum and petrochemical field. In order to produce high quality gas, many companies all over the world including Algeria create many plants for natural gas processing to clean raw natural gas, by using separation unites and other services to get a product that respect the commercial specifications. Natural gas fractions are separated by distillation column in our case is called deethanizer tower. In this work a dynamic simulation study of deethanizer column is developed and implemented in HYSYS simulator. Simulation results prove that the HYSYS is a powerful tool to simulate industrial processes such that the simulated results are close to the real ones.
\end{abstract}

Keywords: natural gas processing, deethanizer, simulation, HYSYS simulator.

\section{INTRODUCTION}

Natural gas is the most energy-efficient fossil fuel; it offers important energy-saving benefits when it is used instead of oil or coal. Although the primary use of natural gas is as a fuel, it is also a source of hydrocarbons for petrochemical feedstocks and major source of elemental sulfur, an important industrial chemical. Its popularity as an energy source is expected to grow substantially in the future because natural gas can help achieve two important energy goals for the twenty first century: providing the sustainable energy supplies and services needed for social and economic development and reducing adverse impact on global climate and the environment in general [1].

The current developments are marked by greater competition between available sources and dynamic companies, that's why the gas map has been redrawing with new discoveries, for that the traditional natural gas companies are forced to recheck their strategy with changing markets and using new technologies [2].

To adapt new technologies or revisions for an existing process, an important step should be realized where the dynamic simulation using

some powerful softwares are considered. Among these softwares HYSYS is very important since it provides not only dynamic tools but also analytical tools for optimization of any considered process. Our work is included the field of dynamic simulation of gas processes using HYSYS simulator.

\section{PRESENTATION OF THE SONATRACH FIRST CALGARY PETROLEUM (SHFCP)}

The Menzel Ledjmet East (MLE) natural gas and liquids project was undertaken by ENI and Sonatrach on block 405B in the Berkine basin. The SHFCP works on two trains: the MLE Wet Gas Field that has just come on stream and the Central Area Field Complex (CAFC). The MLE field is situated on block 405B in the Berkine basin Algeria about 220 $\mathrm{km}$ in south-east Of Hassi- Messaoud (Fig.1) [3].

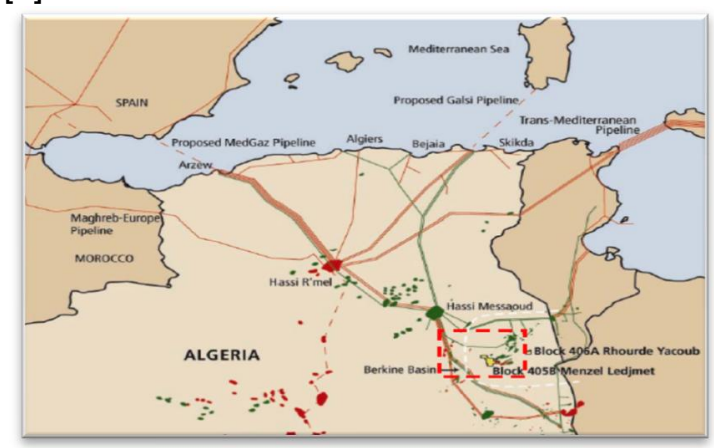

Fig. 1 Geographic Situation of MLE field.

The MLE project included in particular:

- 24 gas wells and 6 manifolds of gas 
collectors;

- A central processing facility (CPF) that includes gas compression for sale, CO2 removal, LPG extraction, oil and condensate stabilization, product storage and pumping system;

- Related services;

- 4 export pipelines of gas for sale, condensate, LPG and oil.

The CPF plant facilities process the well fluids to produce sales gas that meets the calorific value specification; condensate and oil that meet the vapor pressure and density specifications and LPG that meets the required composition specifications (Fig.2) [3].

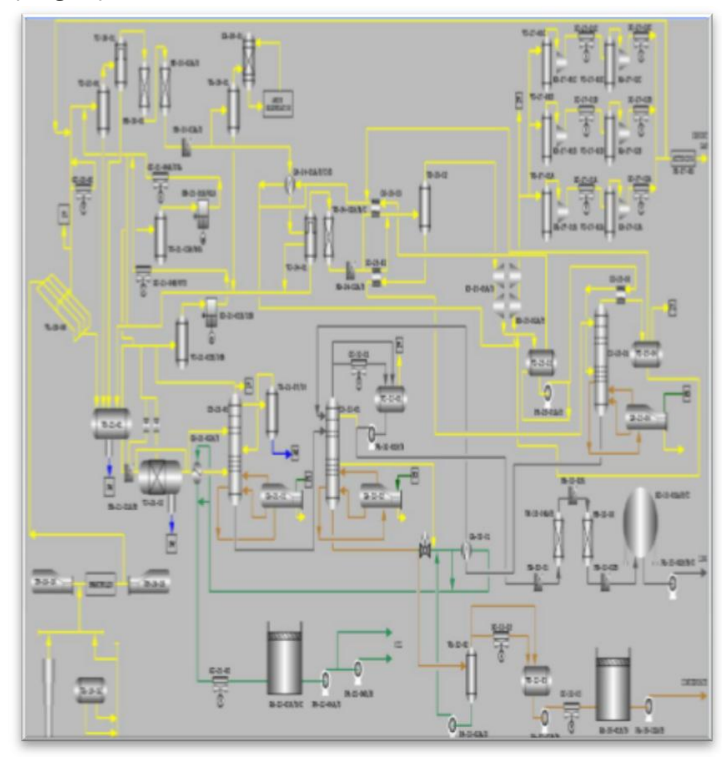

Fig. 2 The CPF plant facilities.

\subsection{THE FIRST CALGARY PETROLEUM PROCESS (FCP)}

The MLE project treatment plant collects and treats fluids that were extracted from MLE wells and those from CAFC wells:

- Gas for sale must meet the specification of the calorific value;

- Condensate must meet the specification of the vapor pressure;

- Oil that must meet the specification of vapor pressure and density;

- LPG that must meet the specification of the required components [3].

\section{NATURAL GAS PROCESSING}

Natural gas processing is a complex industrial process designed to clean raw natural gas by separating impurities and various non-methane hydrocarbons and fluids to produce what is known as pipeline quality dry natural gas[4].

Natural gas processing plants purify raw natural gas by removing common contaminants such as water, carbon dioxide (CO2) and hydrogen sulfide (H2S) also the mercury $(\mathrm{Hg})$ in some regions. Some of the substances which contaminate natural gas have economic value and are further processed or sold. A fully operational plant delivers pipeline-quality dry natural gas that can be used as fuel by residential, commercial and industrial consumers [5].

\subsection{ROLE OF FIELD PROCESSING FACILITIES}

The role of treatment facilities can be defined in the points[3]:

- Treat to deliver oil with respecting commercial or technical specifications and safely;

- Reject non-marketable effluents without polluting the environment and ensuring the protection of staff, facilities;

- Optimizing the recovery of hydrocarbons in natural gas fields (recovery of condensates).

\section{SIMULATION AND MODELING}

Modeling and simulation is the use of models, which can be physical, mathematical or otherwise logical representation of a system. Both of this approach can facilitate understanding a system behavior without actually testing the system in the real world. Simulation and modeling are included in the body of knowledge of engineering where industries can gain the quality of products and systems and reduce costs which means wining against the real world by using models [6]. When the actual system becomes too complex and may variables are at stake here the modeling intervenes to take care of and treat the problems: a model is elaborated to try to account the complexity of the system by trying to reduce the number of parameters [7]. The procedure is shown in Fig.3.

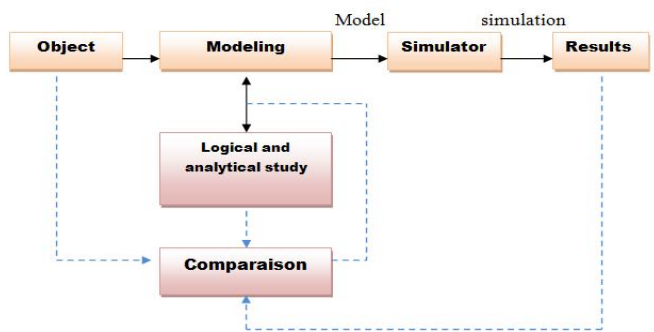

Fig. 3 simulation and modeling procedure 
System analysis, modeling and simulation are three fundamental steps in the study of the dynamic behavior of a complex system. Two types of simulation can be distinguished in chemical processes which are static simulation (steady state) and dynamic simulation (transient state)

- The steady state simulation of a process aims to define the properties of the flows (flow, temperature, vaporized fraction...), also the material and energy balances in stabilized regime. The process subdivides into blocks representing the different unit operation implemented the blocks are linked together by flows of matter or energy;

- The dynamic simulation aims to define the properties of the current as a function of time, during transient situations where the regime is not stable[8].

\subsection{HYSYS SIMULATOR}

HYSYS is not the most flexible nor the most widely simulation software used in the industry, but it has the advantage of being the easiest software once the basics are understood[9].

HYSYS was developed for the petroleum industry; it was designed to handle a wide range of problems ranging from bi and triphasic separations, from compression to distillation and chemical transformations, although it is used for other chemical processes types.

Simulations are accomplished to use the menu tools in addition it has a graphical interface for the construction of the process flow diagrams (PFD).A large pure bodies database is incorporated with the HYSYS software this bodies are grouped into several families:

- Hydrocarbons: normal paraffins and iso paraffins, olefins, naphthalene, aromatic;

- Oxygenated hydrocarbons, nitrogens and sulphides (amine, alcohol, nitriles, aldyhydes), etc ;

- Halogen;

- Solids (sulfur);

- Hypothetical bodies (pure, complex, solid);

- Various $\left(\mathrm{O}_{2}, \mathrm{CO}_{2}, \mathrm{~N}_{2}, \mathrm{H}_{2} \mathrm{O} \ldots\right)$ [10].

\subsection{HYSYS THERMODYNAMIC} MODELS

HYSYS present many thermodynamic models which are used in many application field, we have:

- Special model for the amines;

- Models using vapor pressure (Antoine's equation, NK10 and ESSO table);

- Special model for water vapor (ASTM stream, NBS stream);

- Semi empirical model;

- Hybrid model (for systems which has high polarity, strong deviation from ideality, azeotropic);

- Model based on state equations, like Peng-Robinson (PR), Soave-Redlickkwong (SRK); the application field of these models is in calculating the equilibrium between the phases;

- Adding to SRK, PR, Lee-Kesterplocker's EDE (LKP) should be added, their preferred field is refining, petrochemical, and gas processing industry[11].

So the simulator HYSYS is a set of mathematical models of unitary operations (balloon, distillation column, compressor, valve....etc), these operations are connected in a PFD a process flow diagram [12].

\subsection{HYSYS BASICS}

- Start HYSYS;

- Select components;

- Define and select fluid packages;

- Enter and Re-enter simulation environment;

- Add and specify material streams (Fig.4) [13].

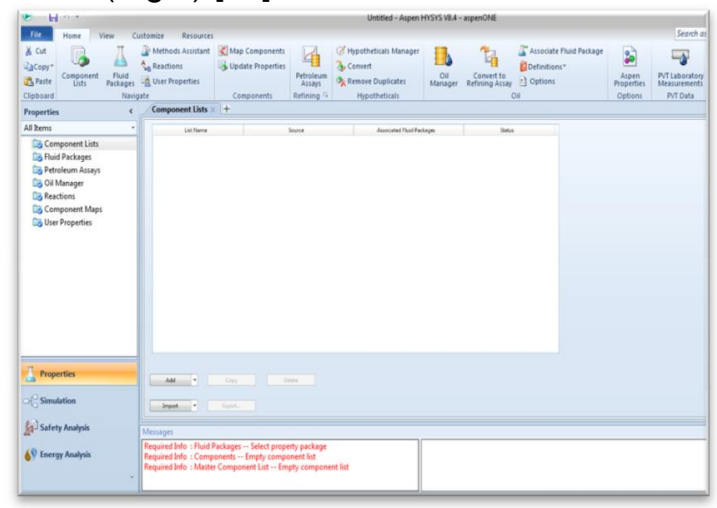

Fig. 4 Work environment. 


\section{DEETHANIZER UNIT AND SIMULATION}

Distillation is one of the most popular methods of separation in petrochemical and chemical industries. Therefore the dynamic simulation of such a system enables a better understanding of its behavior after changing an input parameter[14].

The purpose of this work is to use HYSYS to simulate a deethanizer column at a natural gas recovery unit with a comparison of simulation results with real measured data.

The deethanizer is designed to separate ethane and lighter components from propane and heavy components. Ethane comes out at the top of the column while the heavy products come out as bottom products and fed the debutanizer [15](Fig 4).

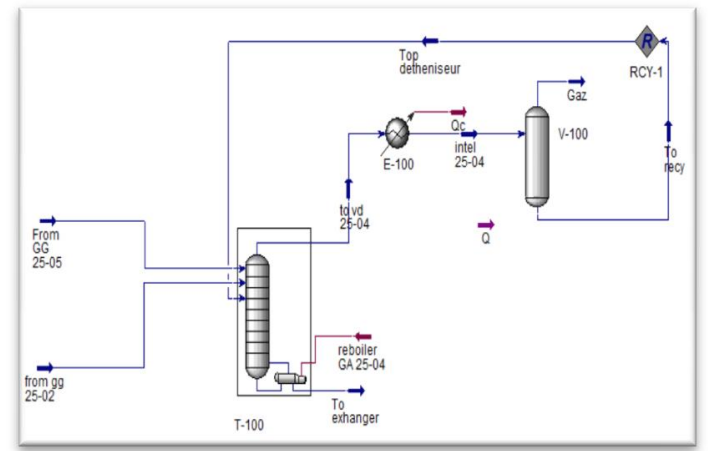

Fig. 5 Deethanizer flowsheet

The deethanizer is composed of 28 trays with parameters which are:

$$
\begin{aligned}
& \mathrm{P}=19.5 \mathrm{barg} ; \\
& \mathrm{T}=-4^{\circ} \mathrm{C} \text { (head temperature); } \\
& \mathrm{T}=83^{\circ} \mathrm{C} \text { (Background temperature). }
\end{aligned}
$$

The first cold feed comes from the expander and enters the top of the column in the first stage while the second hot feed consisting of vaporized liquids comes from the bottom of the balloon (VD-25-02) which feeds the 14th stage. The reflux flow is ensured by a part of the flask gas (VD-25-04) cooled via the exchanger (GC-25-05) (Fig.5).

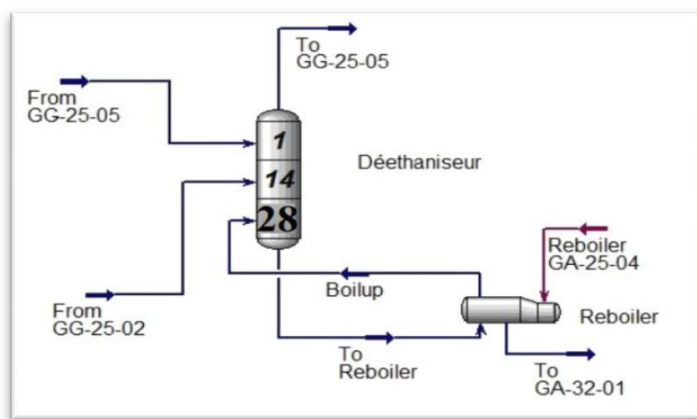

Fig. 6 process design

\subsection{FEED CHARACTERISTICS}

In the current case a physicochemical characteristics such as the nature of the charge and the products endpoints and operating parameters were taken into account for the purposes of the simulation.

From GG-25-05, The charge comes from the exchanger GG-25-05 feeds the deethanizer in the first stage, with a flow of $5 \mathrm{~m} 3 / \mathrm{h}$ and a temperature of $4^{\circ} \mathrm{C}$ and a pressure of 19.5 bar.

From GG-25-02, The charge comes from the exchanger GG-25-02 feeds the deethanizer at the 14th stage, with a flow of $23900 \mathrm{~kg} / \mathrm{h}$ and a temperature of $23^{\circ} \mathrm{C}$ and a pressure of 19.5 bar.

\subsection{OPERATIVE PARAMETERS OF DEETHANIZER}

The simulation was performed using the real parameters of the deethanizer such as the pressure of two loads 19.5 bar and bottom 19.5 bar, the bottom temperature that equals $83^{\circ} \mathrm{C}$ and $0^{\circ} \mathrm{C}$ at the summit. These data are grouped in the following table (table 1).

Table 1 operative parameters of deethanizer

\begin{tabular}{|c|r|c|}
\hline \multicolumn{2}{|c|}{} & $\begin{array}{c}\text { Allowable } \\
\text { interval }\end{array}$ \\
\hline Stage number & 28 & - \\
\hline Feed stages & 1 & - \\
\hline Summit pressure & 19.5 bar & {$[19,31]$ bar } \\
\hline Bottom pressure & 19.5 bar & {$[17.5,31]$ bar } \\
\hline Summit temperature & $4^{\circ} \mathrm{C}$ & {$[-40,12]^{\circ} \mathrm{C}$} \\
\hline Bottom temperature & $83^{\circ} \mathrm{C}$ & {$\left[60,110{ }^{\circ} \mathrm{C}\right.$} \\
\hline
\end{tabular}

\section{SIMULATION AND RESULTS}

After selecting the composition and specifications of the inputs which feeds the tower, by using HYSYS software, we are going to simulate deethanizer tower in order to separate the mixture and getting high fraction on ethane. In this simulation case we 
will use the Peng-Robinson equation of state as a thermodynamic model.

Simulation results of the deethanizer are shown in the table below (table 2).

Table 2 charge and product characteristics of the deethanizer

\begin{tabular}{|c|c|c|c|c|}
\hline & $\begin{array}{c}\text { From } \\
\text { GG- } \\
25-05\end{array}$ & $\begin{array}{c}\text { From } \\
\text { GG- } \\
25-02\end{array}$ & $\begin{array}{l}\text { To } \\
\text { exchan } \\
\text { ger }\end{array}$ & $\begin{array}{l}\text { Fuel } \\
\text { gas }\end{array}$ \\
\hline Vapor & 0.799 & 0.740 & 0.000 & 0.000 \\
\hline $\begin{array}{l}\text { Tempéra } \\
\text { ture }{ }^{\circ} \mathrm{C}\end{array}$ & 1 & 23 & 83 & -35 \\
\hline $\begin{array}{c}\text { Pressure } \\
\text { bar }\end{array}$ & 19.5 & 19.5 & 19.5 & 19.5 \\
\hline $\begin{array}{c}\text { Molar } \\
\text { flow } \\
\text { kgmole/h }\end{array}$ & 521 & 695 & 343 & 873 \\
\hline $\begin{array}{c}\text { Mass } \\
\text { flow } \mathrm{kg} / \mathrm{h}\end{array}$ & $\begin{array}{c}1567 \\
0\end{array}$ & 23900 & 19405 & 23031 \\
\hline $\begin{array}{l}\text { Liq } \\
\text { volume } \\
\text { flow } \\
\mathrm{m} 3 / \mathrm{h}\end{array}$ & 40 & 53.58 & 34.17 & 63.13 \\
\hline
\end{tabular}

Curves results

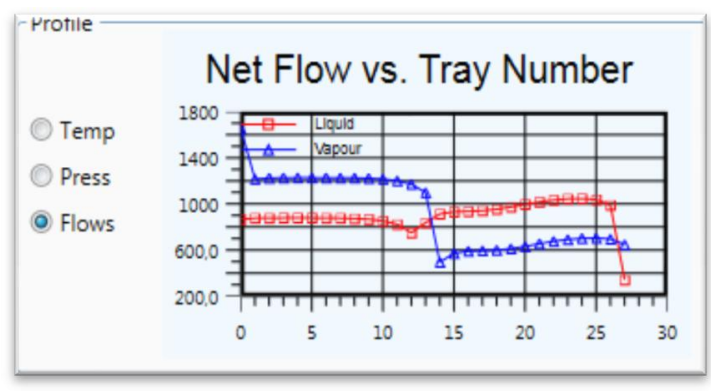

Fig. 7 liquid vapor flow profile in the deethanizer.

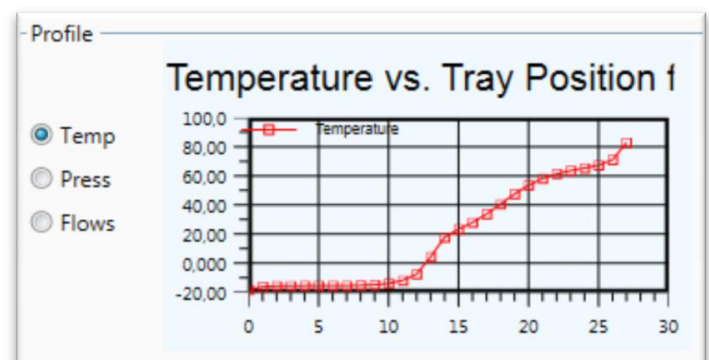

Fig. 8 Température profile.

In this work the simulation of the deethanizer unit is carried out using Peng-Robinson equation; as it is shown in Fig7 and Fig 8 the profile of temperature and vapor flow with respect tray positions are indicated the resulted data are approximately the same with those given by the real data. and So the simulation results are close to the real ones which prove that HYSYS is a powerful tool to simulate industrial processes.

\section{CONCLUSION}

The work presented in this report is a result of training in the operation department of the MLE SH-FCP complex.

The initial objective of this work is to simulate and optimize a distillation columndeethanizer and compare the results with those of the design.

Aspen HYSYS 8.4 is powerful software that presents very important features to implement efficient process dynamic simulation, the fact that is investigated by our work on the simulation of the deethanizer. The results given by HYSYS are approximately the same with those provides by the association. To realize the project we have presented a deep description for HYSYS, how to generate a project under HYSYS and analysis methods provided by HYSYS.

\section{References}

[1]. B.MDM, "Natural Gas treatment ", Algerian 
petroleum institute, 2014.

[2]. J.Johnston, R.Blakemore, R.Bell, "THE ROLE OF OIL AND GAS COMPANIES IN THE ENERGY TRANSITION",January 2020.

[3]. SH-FCP, Process Operation Manual, MLE Project, Block 405B, Algeria, SH-FCP, 2009.

[4]. Saeid Mokhatab, Y. Mak, in "Handbook of Natural Gas Transmission and Processing", Third Edition, 2015

[5]. A.Rojer, C.Jaffret, "Natural Gas", éditons technip, Paris : IFP, 1997, p.243-258

[6]. Department of Defense INSTRUCTION NUMBER 5000.61, "Modeling and Simulation (M\&S) Verification, Validation, and Accreditation".December 09, 2009.

[7]. R.Zerrouk, T.Manane, "Optimisation et Simulation des Pertes du glycol au niveau de la section de déshydratation dans l'unité (RGTE) à In Amenas par HYSYS“, Mémoire de Master Académique, Université KASDI MERBAH OUARGLA, juin.2013.

[8]. Paul I. Barton, "DYNAMIC MODELLING AND SIMULATION", july 1997

[9]. E.Hanyak, "Chemical Process Simulation and the aspen HYSYS software", Copyright 1998 to 2012.

[10]. HYSYS Process Documentation, Hyprotech, Ing, AEA Group, Calgary, 2000.

[11]. Aspen Process Engineering Webinar, "Aspen HYSYS Property Packages, October 17,2006.

[12]. D. Abdelbasset, "Simulation D'une Unité De Production De Méthanol à L'aide De L'ASPEN PLUS-HYSYS“, Mémoire de Master, Université Mohamed Khider, Biskra, Juin 2014.

[13]. Wilcox, R. William, "Hyprotech simulation software for industry ", University of Calgary. Retrieved on 10 December 2016.

[14]. M. Nasseredine, "Simulation et optimisation des paramètres technologies de l'unité de fractionnement des GPL à Haoud Barkaoui", Mémoire de Magister, Université M'Hamed Bougara, BOUMERDES, 2013.

[15]. P.Wauquier, procédés de sparation, vol 2, éditions technip, Paris :IFP, 1998,p.95-104 